\title{
Intercultural marketing: Culture and its influence on the efficiency of Facebook marketing communication
}

\author{
Lukáš COPUŠ \\ Comenius University, Faculty of Management, Bratislava, Slovakia \\ lukas@copus.sk \\ Karol ČARNOGURSKÝ \\ Catholic University, Faculty of Education, Ruzomberok, Slovakia
}

\begin{abstract}
The paper deals with intercultural marketing, which is a combination of two different phenomena - marketing and culture. The first objective of the paper lies in providing theoretical definitions of the above-mentioned areas. Subsequently, the aim is to analyse marketing communication of the selected automotive companies and determine its efficiency on social media within the context of cultural differences and cultural forms as their manifestations. A considerable amount of literature has been published on intercultural marketing, but only a few studies have concentrated on the connection with modern communication tools - i.e. social media. The data come from a research conducted online focused on Facebook. In total 2606 posts on twenty Facebook profiles of selected automotive companies were analysed. Our findings show that the use of standardization and adaptation is not related to the efficiency of marketing communication of individual Facebook profiles. One of the factors that determine the efficiency is cultural specifics visible by cultural forms which were interpreted for each selected culture. The contribution and the originality of this paper lies in providing theoretical and practical information about cultural differences on social media not only for marketing managers operating in different cultures, but also for researchers interested in intercultural marketing.
\end{abstract}

Keywords: intercultural marketing, national culture, cultural forms, social media, Facebook.

Please cite the article as follows: Copuš, L. and Čarnogurský, K. (2017), "Intercultural marketing: Culture and its influence on the efficiency of Facebook marketing communication", Management \& Marketing. Challenges for the Knowledge Society, Vol. 12, No. 2, pp. 189-207. DOI: 10.1515/mmcks-2017-0012.

\section{Introduction and theoretical background}

In the current era of globalization and internationalization, companies and organizations have been searching for new opportunities for developing and expanding their activities especially outside the domestic market they operate in. Their success in new markets is not conditioned only by the production of a good quality product, provision of popular services or well-run marketing activities that are successful in their country. Contrary to local environment, the choice of the right marketing communication in international business is influenced by a new aspect cultural differences between nations. Therefore, besides a shift towards international environment, we can also observe a shift towards international and intercultural marketing. While people and their behaviour are daily influenced by culture they are a part of, virtual environment of social media has recently become one of the vital parts of their daily life. 
As recent trends in marketing communication have shown that the virtual environment has its significance and influence, traditional media forms such as print and broadcasting are now being used less (Schultz et al., 2013; Naylor et al., 2012). Recent empirical studies highlight that companies invest larger shares of their expenses for communication on social media (Hudson et al., 2016; Direction, 2016), because social media are becoming a powerful tool for attracting customers (Guo et al., 2015). Most aspects of marketing communication are integrated predominantly into the area of social media (Schultz et al., 2013). Mainly the Internet environment and its increasing significance started to play a vital role in motivating customers in their decision whether to buy a product or not (Järvinen et al., 2016). The great advantage of social media (apart from others) is the fact that they are available for all sorts of businesses - no matter their size and specialization. Using social media has therefore a big potential to provide a synergic form of interaction for a high number of customers (Kilgour et al., 2014). That is why the social media platforms such as Facebook, Twitter and LinkedIn provide absolutely new ways for businesses to communicate with their customers and why social media are becoming a significant platform for creating customer values (Dessart et al., 2015; Hamilton et al., 2016; He et al., 2015). As many professional sources (Sharma et al., 2016; Azar et al., 2016) reference to Facebook as the most used and largest social media, the authors of this paper decided to use this platform for the purposes of the study.

In general, there are two main reasons why the influence of social media and of Facebook as a social media platform has increased. On the one hand, companies are more intensively than ever looking for new ways for communicating more efficiently, because it has become more challenging to attract the targeted generation of customers (Hamilton et al., 2016). From another point of view, customers are more prone to get influenced by their friends and colleagues while forming their attitudes towards brands and while deciding whether or not to buy a product (Hamilton et al., 2016). Before the rise of social media, this factor in the formation of expectations involved mainly personal communication with persons with whom customers already had a close relationship (Hrnčiar et al., 2016).

Companies should connect with the customers on emotional grounds (Telang et al., 2016) and thanks to social media, business can build such emotional relations with their customers based on the mutual interaction in the online community (Valos et al., 2016). One of the ways of attracting customers through social media is to engage them into open and transparent communication (Karjaluoto et al., 2015). While enabling two-way communication, businesses gain important inputs from customers faster than ever (Hudson et al., 2016). This form of cooperation thus enhances better understanding of customer needs (Karjaluoto et al., 2015).

Therefore, social media can be used as a traditional, integrated marketing tool that helps businesses control a content, timing and frequency of information they share with customers (Gonzalez-Lafaysse et al., 2016). On the other hand, social media provide means that enable mutual communication between businesses and customers (Guo et al., 2015). If businesses want to use the full potential of social media and enhance marketing communication (Gong et al., 2014), they have to adjust their marketing goal to the needs of building relationship and loyalty of 
consumers to a brand through their mutual interaction (Hudson et al., 2016). Thanks to providing customer support and maintaining their loyalty in the social media environment, two-way communication is easier to reach (Karjaluoto et al., 2015). Therefore, it is worth noting that social media present dominant digital communication channel that enables customers to gain and share information about selected brands (Hudson, 2016) and enables businesses to offer as much up to date information as possible - for instance information about products, services and planned events (Icha et al., 2016). This kind of prompt two-way communication brings a lot of benefits, but since the world is becoming global, it also brings some challenges. One of the issues is different perception of needs of specific customer groups due to cultural differences that might influence the overall success and efficiency of marketing communication on social media.

It might be concluded that businesses, or marketing professionals need to learn how to communicate with their target group on social media efficiently (Kwok et al., 2013), putting emphasis on the values, business targets and business sector of a company. To a certain extent, they need to bear in mind the specifics of their target group. Nevertheless, what does an efficient marketing communication mean and how can it be measured? In general, efficiency is the comparison of what is actually produced or performed with what can be achieved with the same consumption of resources. One of the simplest ways of measuring marketing communication efficiency on social media Facebook is publicly available metric "Talking about this", which is specific for each company profile on Facebook. The metric shows userinitiated activity related to the marketing activity of selected company profiles. The profile that can obtain more activity of its users with a number of posts comparable to another profile, is therefore more efficient.

The above mentioned theoretical framework poses several questions, for instance how to implement and adjust the marketing strategy and social media communication in order to make it as efficient as possible. At the same time, it is questionable whether marketing communication on social media should be adjusted to the specifics of national cultures by the same means as those of traditional marketing communication. According to Kotler et al. (2007), companies entering international market can decide between two basic strategic approaches: (a) standardization - implementation of domestic marketing mix to international markets; and (b) adaptation - marketing mix adaptation based on the target market requirements under its cultural conditions for the purpose of achieving improved competitiveness.

The above mentioned cultural conditions and mainly national culture are important for the purpose of this paper, due to the fact that these factors determine potential success of companies at the entry to new markets from the perspective of customer behaviour. The process of forming national culture is influenced by many factors, one of them being historical events that happened in individual countries. These considerations imply that we can find some intersections of national cultures. Regarding their similarities, we selected four cultural clusters in Europe that served as a basis for selecting the automotive companies analysed in this study: Germanic 
Europe cluster, Latin Europe cluster, Nordic Europe cluster, Anglo cluster (Šajgalíková et al., 2016).

It is a challenge to identify culture (its essential core) and even more challenging to quantify it. However, it is possible to study its outer manifestations the so called cultural forms. There are only a few studies that have focused on how culture influences the effectiveness of social media marketing strategy. The results of study conducted on Facebook by Khan et al. (2016) which focused on five different brands of a single category in three different countries showed that the number of likes, comments and shares vary across different cultures. But if we want to understand the nature of such results, we need to understand the culture. And if we want to understand culture, we need to interpret cultural forms, since they stem from invisible and intangible values, credos and norms that represent the essential core of culture (Šajgalíková et al., 2016). Trice and Beyer (1993) classify cultural forms into four categories: symbols, language, histories and activities. These cultural forms can also be identified in the environment of social media and in their use for marketing purposes. Culture and its forms are perceived mainly against the background of other cultures (a contrastive approach). Intercultural marketing is therefore an appropriate concept for researching how significantly culture can be reflected in international business and how much impact it has on marketing activities.

\section{Research methodology}

The aim of the study is to examine the differences in marketing communication of selected automotive companies and its efficiency on Facebook as a social media platform, with regard to cultural differences demonstrated in cultural forms. To accomplish the objectives set forth, official Facebook profiles of selected automotive companies were analysed. We gathered data from 06/2016 to 12/2016.

The process of selecting automotive companies was influenced mainly by the cultural specifics of the individual states. As mentioned in the theoretical framework of this study, four cultural clusters can be identified in Europe according to their similarities and intersections. The following countries can be identified as typical representatives of the clusters: Germany (Germanic Europe cluster), France (Latin Europe cluster), Sweden (Nordic Europe cluster) and Great Britain (Anglo cluster). Even though the proprietary structure of automotive companies is no longer based only on national basis (shareholders from different countries own capital participation), and cars are not produced only in a home country of the automotive company, it is possible to select companies typical for the above mentioned stated and thus cultural clusters as well: Germany - Volkswagen, France - Peugeot, Sweden - Volvo, Great Britain - Land Rover.

Based on the given cultural clusters, countries and individual automotive companies, official companies' profiles were analysed on Facebook. We analysed five profiles of each of the selected automotive companies, whilst we chose official company profiles of the following, already mentioned, countries: Germany, France, Sweden, Great Britain as well as Slovakia (as the authors' native country).

The following scheme illustrates processes needed to accomplish the desired research objective: 


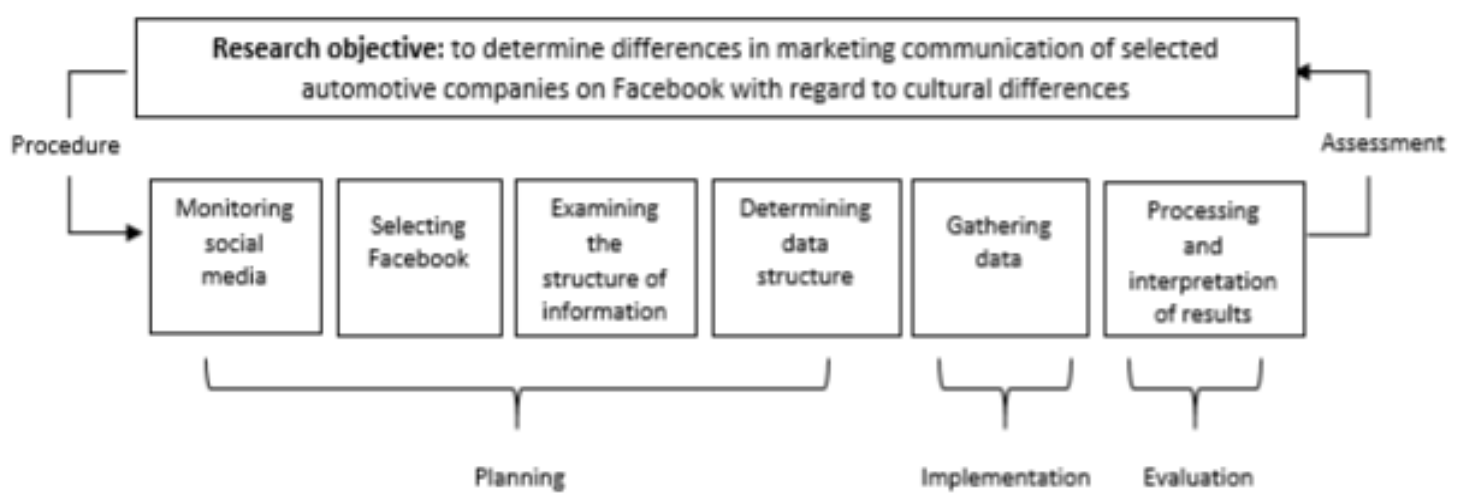

Figure 1. Processes needed to accomplish the desired research objective

Source: Authors' own information.

In order to meet the desired research objectives, the following steps were undertaken:

(1) Determining the total number of posts, requiring laborious calculations.

(2) Contacting profile administrators of the automotive companies in an attempt to obtain more detailed information about marketing communication of particular automotive companies on Facebook.

(3) Analysing posts with the aim to determine the extent to which automotive companies in individual countries use elements of standardization and adaptation within intercultural marketing.

The first profile to analyse was in each case the profile of a home country of the automotive company. The profile of the country which the automotive company comes from (for instance Sweden as a country of origin for Volvo) was selected as a primary (home) profile of each automotive company. Then the profiles of the particular automotive company were analysed even in other states regarding defined cultural clusters. In order to determine the extent to which standardization and adaptation were used, it was necessary to define which posts can be considered as own posts, generated by the individual profiles and which are adapted, consistent with all profiles within one automotive company. Only the posts which could be unambiguously identified as "unique" for the given profile were considered as own posts. Photos, videos, events, contests or sportsmen popular in the given country (steering wheel placement on the left side - Great Britain, the Eiffel Tower - France, etc.) can serve as an illustrative example.

(4) Quantitative determination of the extent of adaptation and standardization of the individual profiles and automotive companies based on the collected data. The higher the own posts' representation is, the lower the extent of adaptation is and vice versa.

(5) Obtaining information about active users on the basis of publicly available variable "Talking about this", which expresses activity of fans of particular profiles caused by activity of the profile (likes, shares, comments, etc.).

(6) Analysis of marketing communication efficiency based on the information on active users (fans of particular profiles caused by activity of the profile) and a 
number of posts. As the countries have different numbers of active Facebook users, a method of scaling was used. This method was based on active Facebook user data in a given country.

(7) Analysis and interpretation of cultural forms which can be found in individual countries on the above-mentioned profiles. Each post was analysed in order to identify and subsequently interpret the impact of national culture of the individual states on Facebook marketing communication of automotive companies as well as to determine the extent to which the posts are specifically adapted to the given culture. The objective was also to determine the extent to which cultural specifics relate to marketing communication efficiency.

Results were processed into graphs whilst their interpretation was indicated in the form of a text. Findings were integrated into a summary table of cultural forms for the given countries. Quantification of these views enabled us to summarize some conclusions for future scientific and practical discussion.

\section{Results and discussion}

\section{Standardization vs. adaptation}

Based on the marketing communication analysis in the form of individual Facebook posts, we have set a quantitative analysis of the extent to which automotive companies use standardization and adaptation elements within intercultural marketing. Table 1 presents the total number of posts of the given profile, the number of own posts of the given profile and the percentage of own posts of the profiles in the selected countries.

Table 1. Overall activity overview of selected profiles

\begin{tabular}{|c|c|c|c|c|c|c|}
\hline & Sweden & Germany & France & $\begin{array}{c}\text { Great } \\
\text { Britain }\end{array}$ & Slovakia & \\
\hline \multirow{3}{*}{ Volvo } & 121 & 161 & 154 & 70 & 151 & all posts \\
\hline & $\mathrm{X}$ & 68 & 57 & 28 & 26 & own posts \\
\hline & $\mathrm{X}$ & $42,24 \%$ & $37,01 \%$ & $40,00 \%$ & $17,22 \%$ & $\begin{array}{c}\% \text { of own posts on all } \\
\text { posts }\end{array}$ \\
\hline \multirow{3}{*}{ Volkswagen } & 71 & 200 & 165 & 96 & 149 & all posts \\
\hline & 33 & $\mathrm{X}$ & 59 & 50 & 46 & own posts \\
\hline & $46,48 \%$ & $\mathrm{X}$ & $35,76 \%$ & $52,08 \%$ & $30,87 \%$ & $\begin{array}{c}\% \text { of own posts on all } \\
\text { posts }\end{array}$ \\
\hline \multirow{3}{*}{ Peugeot } & 80 & 153 & 177 & 227 & 87 & all posts \\
\hline & 27 & 47 & $\mathrm{x}$ & 70 & 56 & own posts \\
\hline & $33,75 \%$ & $30,72 \%$ & $\mathrm{x}$ & $30,84 \%$ & $64,37 \%$ & $\begin{array}{c}\% \text { of own posts on all } \\
\text { posts }\end{array}$ \\
\hline \multirow{3}{*}{ Land Rover } & 65 & 139 & 127 & 61 & 152 & all posts \\
\hline & 9 & 30 & 38 & $\mathrm{X}$ & 12 & own posts \\
\hline & $13,85 \%$ & $21,58 \%$ & $29,92 \%$ & $\mathrm{X}$ & $7,89 \%$ & $\begin{array}{c}\% \text { of own posts on all } \\
\text { posts }\end{array}$ \\
\hline
\end{tabular}

Source: Authors' own research.

Figure 2 provides a graphical representation of the results. The blue section of each column indicates original posts (adopted posts, mainly from the primary, 
home Facebook profile of the automotive company) and the orange section indicates own posts. As we supposed that profiles in individual states are based on the profile of the home country of the automotive company, we marked all posts posted on the primary Facebook profile as "original".

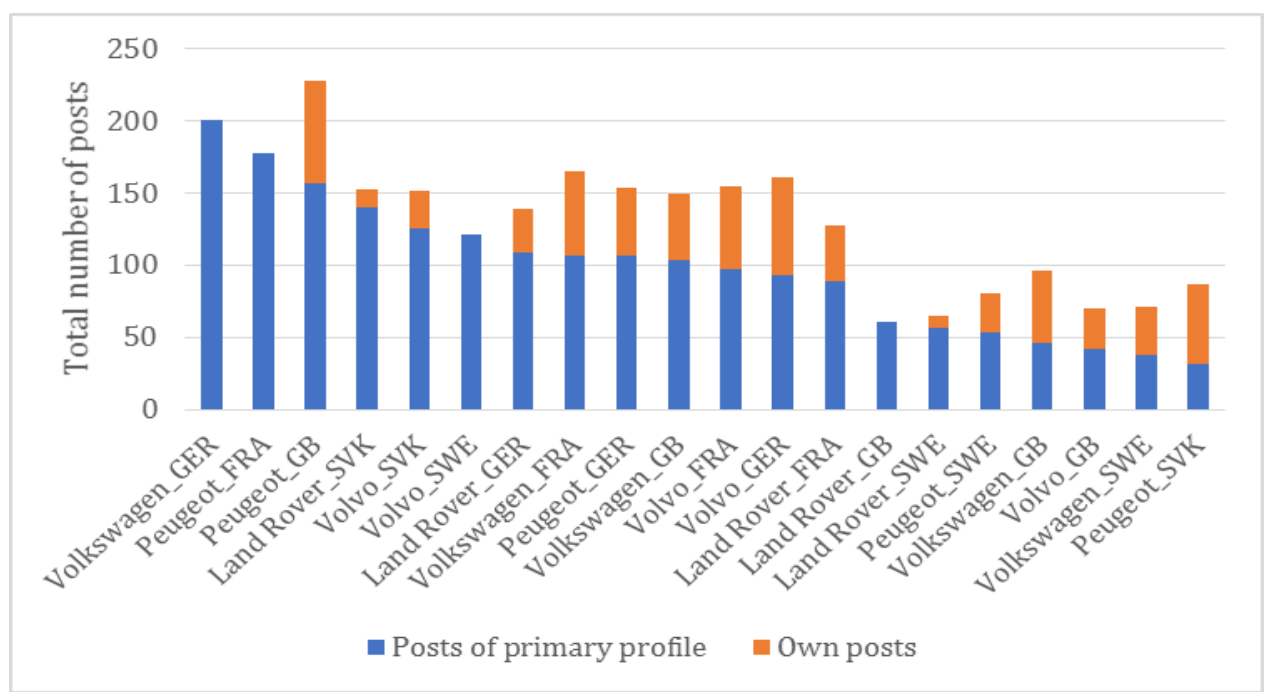

Figure 2. Original and own posts

Source: Authors' own research.

It follows from the above that all automotive companies use the combination of standardization and adaptation. Average values of the automotive companies are listed in Table 2 . The values imply that Land Rover uses mainly standardization as the average percentage of the posts within the category "own" is $18.43 \%$ in all given countries. The overall percentage of "own" posts of Volvo and Peugeot profiles is roughly the same and ranges between $33.40 \%$ and $36.56 \%$, but standardization still prevails on their Facebook profiles. In case of Volkswagen, the situation is different as the percentage of "own" posts is $51.35 \%$ and thus the slight tendency towards adaptation can be observed.

Table 2. Percentage of own posts of automotive companies

\begin{tabular}{|c|c|c|c|c|}
\cline { 2 - 5 } \multicolumn{1}{c|}{} & Volvo & Volkswagen & Peugeot & Land Rover \\
\hline Percentage of own posts & $33,40 \%$ & $51,35 \%$ & $36,56 \%$ & $18,43 \%$ \\
\hline
\end{tabular}

\section{Marketing communication efficiency}

The above-mentioned results are followed by another section of an analysis that is dedicated to the ways of how the use of standardization and adaptation influences marketing communication efficiency on the specific profiles. Figure 3 indicates the relation between the overall number of posts of company profiles and the follow-up fan-initiated activity of the given profile (so called "Talking about this"). The most ideal situation occurs when relatively low-profile activity (a small number of posts) is sufficient enough to initiate as much users' activity as possible (see the point on 
the right side below in the picture). The picture is divided into several segments, whilst the profiles placed in the same segment have similar efficiency.

Volkswagen in France chooses the most efficient marketing communication while Peugeot profile from Great Britain as well as Volkswagen profile from Germany are the least efficient in their Facebook marketing communication. The rate of standardization of Volkswagen profile from France (35.76\% of own posts) and Peugeot profile from Great Britain (30.84\% of own posts) is similar. Therefore, according to the results, marketing communication efficiency does not correspond to the rate of standardization and adaptation. Most probably, marketing communication efficiency must also depend on other factors, and one of these factors might be cultural specifics, as we define in other parts of the study.

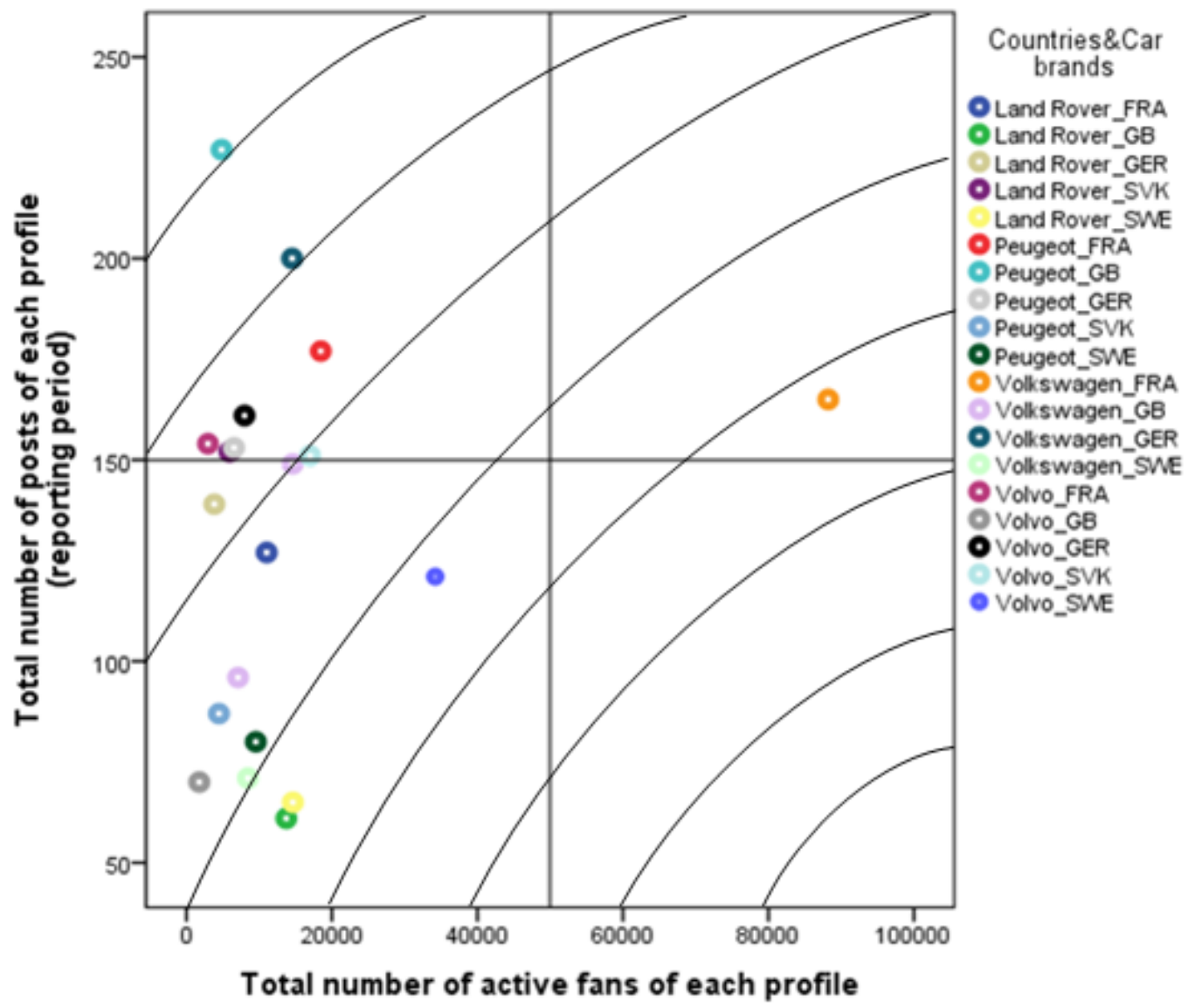

Figure 3. Marketing communication efficiency of each profile

Source: Authors' own research.

If we focus on automotive companies as a whole, Volkswagen has the most efficient marketing communication, is followed by Land Rover and Volvo, while Peugeot has the least efficient communication (see Figure 4). Since no connection between this order and standardization as well as adaptation usage data (Table 2) can be observed, marketing communication efficiency cannot be linked to standardization and adaptation rate even according to these results. Once again, we 
assume that more factors influence efficiency and one of them might be cultural differences discussed in sections to follow.

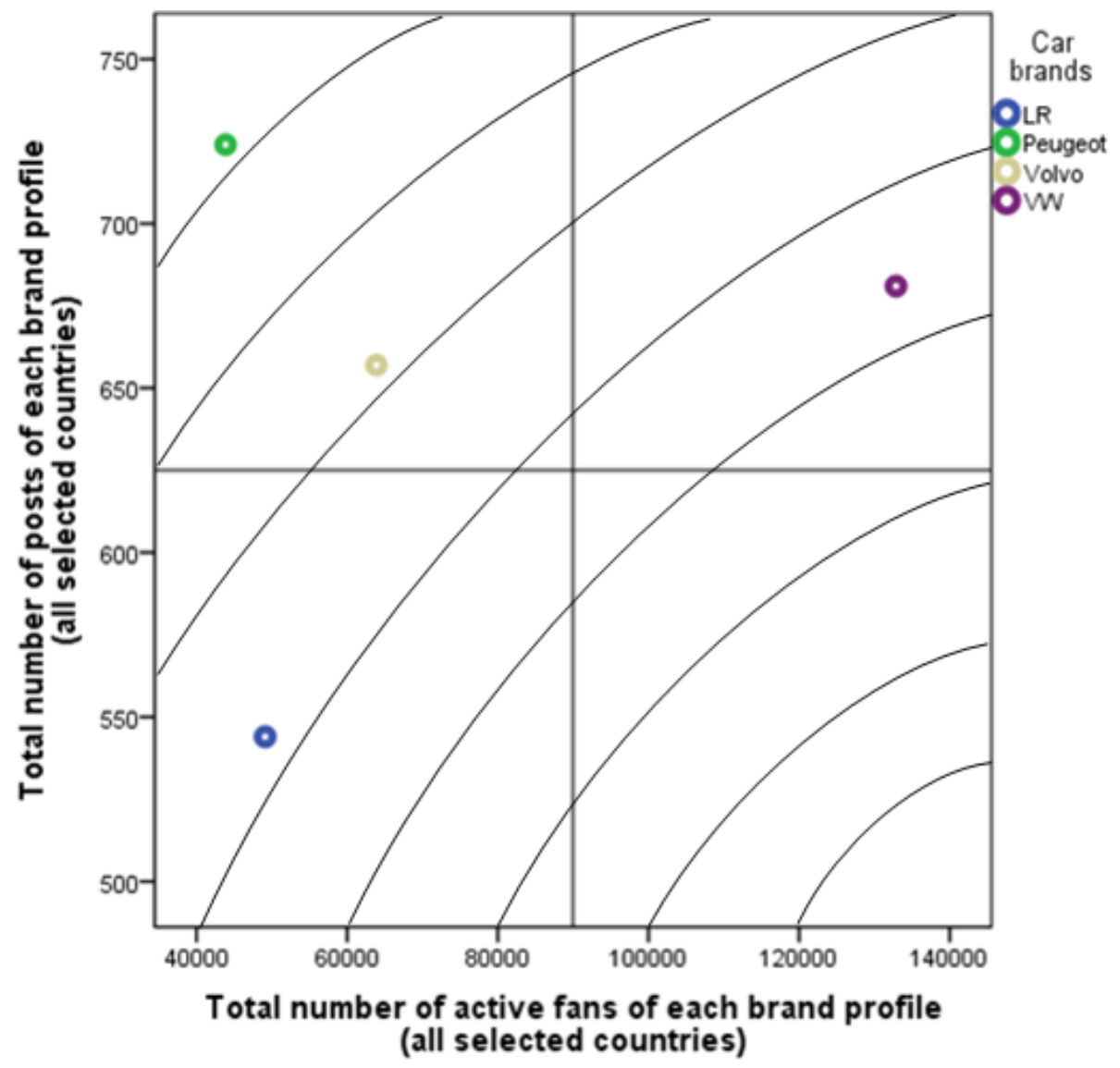

Figure 4. Marketing communication efficiency of the given automotive companies

Source: Authors' own research.

\section{Cultural forms}

Based on the quantitative analysis stated in the former part of the study, it can be concluded that automotive companies combine elements of standardization as well as adaptation within intercultural marketing. However, no relation between their implementation and marketing communication efficiency was found. These results are followed by another part of an analysis that explores the manifestation of national culture in adaptation and standardization and its influence on intercultural marketing and the overall marketing communication efficiency. As cultural forms are observable elements of culture, we focus our attention on them in the section to follow.

\section{Volvo Sweden}

Firstly, we will analyse Volvo and its profile administered in its home country Sweden. Photos, as manifestations of cultural forms, depict mainly rough Nordic and Scandinavian nature where Volvo cars can "endure" thanks to their specifications 
and parameters enabling car passengers safe driving without any complications. The lower number of photos is set in the environment of Swedish cities, but even they illustrate harsh climatic conditions. From the cultural point of view, this form might be interpreted as a historical effort of inhabitants for survival in harsh climate conditions. At that time, a person had to look after himself and live in harmony with nature. In the photo descriptions, we do not find any tendency to present Volvo car as a symbol of social status that enables you to be the fastest driver and to compete with others. In contrast, Volvo is depicted as a car that helps its owner look after himself and "endure", which is the manifestation of individualistic culture. Many posts capture vintage models of Volvo and the fact that they have been helping their owners in the above mentioned hostile life.

\section{Volvo UK}

From the quantitative point of view, the British profile of Volvo has slightly higher percentage of standardization, as $60 \%$ of posts are adopted and $40 \%$ are own posts. Although some posts are adopted and present the Scandinavian style, the nature is not captured on photos that much. Rather people are put at the forefront of photos, for example some famous personalities in the videos. They are presented as people with vison and idea, willing to pursue their passion and successfully convert their dreams into reality. We can interpret it as a manifestation of individualism and masculinity, as an individual's effort to succeed. The Brits are historically known as very active businessmen and pragmatists. Since Britain has been under the dominance (the Roman Empire, Normandy...) for ages, the Brits began to expand rapidly after the Normandy landing and embarked on subjugating the others (they established many colonies). The phenomenon of competitiveness and individual's success is endorsed even today, which has been demonstrated also on Facebook posts.

\section{Volvo Germany}

The German profile created $42.24 \%$ of its own content, which is a figure similar to the British profile and combines the elements of standardization as well as adaptation. Adopted posts present mainly rough Scandinavian nature, but when compared to other profiles, they pay more attention to details, Volvo cars' amenities and accessories that bring much efficiency to their owners. From the cultural point of view, the Germans are very precise, good at detailed planning and work efficiently. It is closely connected with their history, as Germany comprised 2000 individual units until the 19th century. These units could, however, closely cooperate as one coherent whole - "a well-functioning machine". So are the Germans - efficient and precise. Volvo in Germany presents mostly this aspect of their cars. The profile publishes a lot of photos from "ordinary" people, the owners of Volvo cars, who show how well their cars serve them.

\section{Volvo France}

As on the previous profiles, the French profile also combines standardization and adaptation. The percentage of the total number of its own posts is $37.01 \%$. In 
comparison to other profiles of Volvo, it adopts the fewest photos from the Swedish profile. Even though nature remains as the main theme, this profile publishes a lot of its own professional photographs taken in a setting of French towns and monuments as well as the French countryside. From the cultural point of view, a parallel can be drawn with the fact that the past as well as their history (popular history of the French nation) is very important to the French who tend to return to their past and history. They are also known for their sense of uniqueness and gladly leave their "imprint" on everything. The French profile therefore publishes its own photos, which are in connection with France and its history.

\section{Volvo Slovakia}

The Slovak profile, when compared to other profiles, uses the highest percentage of standardization, as only $17 \%$ of its posts fall into a category of "own" posts. The Slovak profile is based mainly on posts from the Swedish and German profile, while its posts adopted from other profiles are almost exclusively photographs and original posts. Own posts of the Slovak profile are usually related to the company's activities in Slovakia. For instance, the profile published some updates on the organized contests (a winner could borrow a Volvo car with a full fuel tank) or on the latest exhibition of Volvo cars.

\section{Summary of Volvo}

As far as intercultural marketing of Volvo is concerned, we can see the combination of standardization and adaptation. Although the profiles in analysed countries are based on the original Swedish profile and present hostile Nordic conditions, each of them adjusts marketing strategy to the local conditions and culture that is specific for the respective country.

Our findings were validated even by administrators of the Facebook profiles. We interviewed an administrator of the Swedish profile who confirmed that in some cases, the profile administrators translate original posts into their native language and in other cases they create their own content with respect to experience from their market background and their social media strategy. An administrator of the French profile provided even more detailed information and explained that when they communicate directly with the French community, their posts must be relevant for the members of the community. On one hand, they follow their general social media guidelines representing company values and ensuring certain amount of uniformity all around the world, which are published and relevant for each country. But at the same time, profile administrators make sure that they adopt these guidelines to the local conditions and French culture. The profile administrators have an access to a large number of photographs and videos that can be shared, but as the profile administrator points out, they put great emphasis on cultural and historical aspects of France.

\section{Peugeot France}

Dominant motives of French Peugeot profile are victories and successes, mainly those of French sportsmen and racers who are connected with Peugeot brand. 
There are a lot of photos and videos in which not only the current successes of the French sportsmen are presented, but also the ones from the past. A video showing 20-year long history of French achievements in various areas, each connected with Peugeot, can serve as an illustrative example. There are also many photos of vintage car models from fans published on the profile. As it was mentioned in the analysis of French Volvo company profile, French culture is focused on the past and present characterized by patriotism. Fame and success are very important for French culture, which is noticeably demonstrated on their profile. It is emphasized by a lot of pictures taken in typical French environment. There are some videos as well in which a powerful boss orders and leads other people. The French people are typical for accepting authorities and hierarchical division of society. This attitude is related to their history and creating a centralized monarchy. However, some posts emphasize that behind every success of an individual stands his team. From the cultural point of view, it can be observed that even though hierarchy is natural, all the employees are appreciated.

\section{Peugeot Sweden}

The Swedish profile of automotive company Peugeot created $33.75 \%$ of their own posts including their own photos. These can be distinguished mainly by Swedish licence plates. These own photos are not taken in extremely hostile environment as can be seen on the profiles of other automotive companies in this country. There is mainly Swedish nature depicted, but it does not evoke such hostile impression. The photos are rather well-stylized and beautiful. Therefore, we can see elements of adaptation on local culture, but only to a limited extent. As noted above, the French are fond of elegance and they like leaving their imprints on everything. This cultural imprint causes that even though there is adaptation used on the profile, the Swedish culture does not come into focus in own profile posts. It is just an unnatural mixture of French and Swedish culture.

\section{Peugeot Germany}

Like on the Swedish profile, there is a similar percentage of posts on the German Peugeot profile where $30.72 \%$ of their own posts can be found. The own posts of this automotive company in Germany are focused on how technologies in Peugeot cars help people with different activities, which is connected with already mentioned need of Germans to be as effective as possible. They also publish photos from their fans. We can see orientation on detail and people, but to a limited extent when compared to Volvo profile in this country. The German profile is very consistent with profiles in other countries and only slight differences can be seen. This profile can be again interpreted as an attempt for French "imprint" where adaptation is used, but the German cultural specifics are not so significantly taken into consideration.

\section{Peugeot UK}

English Peugeot profile is typical for its (even if not very striking) focus on celebrities, for example on a famous British Youtuber, a sportswoman or an editor 
presenting Peugeot automobiles. Support of sportsmen, especially Paralympians, is presented as well. As far as focus on celebrities is concerned, it demonstrates individualism and masculinity regarding cultural point of view. If we compare this tendency with Volvo and Volkswagen profiles from Great Britain, it is less distinctive on Peugeot profiles. The French culture is dominant even on this Facebook profile, which was explained on the example of previous countries. In comparison with other countries, this profile was the least efficient, what can be caused by the above-mentioned reason.

\section{Peugeot Slovakia}

When compared to other profiles, the Slovak Peugeot profile is the most active in publishing its own posts (64.37\%). As the percentage indicates, it uses mainly adaptation. Its own posts are focused on different events organized in cooperation with Peugeot, for example Tenis Slovak Tour, Dievča leta (a Slovak beauty contest) or Légia Tour. Peugeot is also presented as a partner of SND (Slovak National Theatre) and a sponsor of tennis players, who enhance its promotion. Impressions of participants testing cars also come into focus.

\section{Summary of Peugeot}

While analysing Peugeot, a very interesting situation occurred. This automotive company uses a combination of standardization and adaptation, but company's own posts are not so distinctive for a culture of the country in which they adapt. As it was mentioned, it is possible to interpret it as an attempt of the French to leave the imprint of their culture all over the world. This tendency lowers the possibility to adapt the posts of particular profiles to local cultural specifics of other countries. Despite the fact that Peugeot is the most active in publishing posts, we can claim that based on our results, its marketing communication is the least efficient of all companies.

To certain extent, it was confirmed by the Swedish profile administrator. He claimed that profile administrators are trying to create an own content relevant mainly for the Swedish culture, but at the same time, they have to publish a lot of posts coming from the central marketing department that are standard for the company profiles all around the world.

\section{Volkswagen Germany}

German Facebook profile focuses mainly on how useful the Volkswagen cars are for people in their usual activities, such as transfer of the Christmas tree. The profile shows that Volkswagen cars bring the quality life to people, even to their customers with physical disability. Posts are oriented on people, families, friends and their leisure time that in an unobtrusive way includes Volkswagen cars. As German culture strictly divides work life and private life, the Facebook marketing is in this case focused mainly on private life. However, several posts inform about the factory in Wolfsburg, presenting it as an integral part of the city and showing it photographed together with its employees. German companies are well known for their links to environment, in which they operate and they consider also other 
interacting elements, such as cities and their inhabitants. Closely related to this approach are the posts set in nature, with animals. German companies have also a long-term interest in the environmental protection which is a part of their corporate social responsibility. Several posts cover the details of the cars and how the cars meet the needs of people and make them effective. The effectiveness is what defines Germans. The evolution of the model Golf, how the generations of this model improved and underwent innovations, receives relatively large attention. This is mainly related to the working life, when employees carry out their work responsibly, with attention to details and thus they create opportunities for improvement and innovation, which would make them even more effective.

\section{Volkswagen Sweden}

Swedish Facebook profile produced $46.58 \%$ of its own posts and we can feel the influence of the Nordic culture in them. Again, the combination of standardization and adaptation is used. Swedish profile shows own professional photographs and videos of cars set in the Nordic hostile environment, in which cars have to get over difficult natural conditions. As mentioned already, it is related to the historic experience of Swedish people who always had to overcome hostile conditions and survive. Swedish profile is a great supporter of the Swedish ski team; the profile is posting a lot of photographs from the competitions too.

\section{Volkswagen France}

French Facebook profile produced $35.76 \%$ of own posts consisting mainly of photographs of Volkswagen cars from French fans and some own videos. A lot of attention is given to a French rally driver and his international achievements, which show previously mentioned patriotism and effort to present French success. Even though most of the posts in the profile are shared, the profile tries to adapt them to the French culture. It would include the change of the photograph description and so on. Thanks to this strategy, the French profile was proved to be the most efficient in our analysis.

\section{Volkswagen UK}

Within the automotive company Volkswagen, the British Facebook profile shares the least posts from other profiles, $52.08 \%$ of the posts are originally produced by the British profile. It is typical for the profile to focus on well-known and successful people who speak about their life with Volkswagen cars. However, it publishes also the stories of "ordinary" people. As we have already mentioned, this expression of individualism and masculinity is based on their historical experience. The British profile posts a lot of its own professional photographs and videos reflecting the effort to not to adapt to anyone but rather be their own boss. This can be also explained in relation to their historical experience being long time under the rule. However, this profile also gave space to the rally competitor from France racing in the Volkswagen car. Several posts about him were shared from the French profile. Even though he is not a British racer, he represents the achievement of an individual that is so important for the Brits. 


\section{Volkswagen Slovakia}

Activities of the Slovak Facebook profile are influenced by the fact that Volkswagen cars are manufactured in Slovakia. Thus the profile shows own photographs presenting cars as "Made in Slovakia". However, the profile shares many posts from other profiles, mainly videos and photographs, but with the changed description. Own posts are talking about co-organizing the events in Slovakia and deals with contests organized for fans on Facebook.

\section{Summary of Volkswagen}

Even in the case of Volkswagen, we can see the combination of adaptation and standardization. The individual Facebook profiles often use the same photographs but with own descriptions. The posts are shared from the German profile, as well as from other profiles. Unlike Peugeot, which also used the combination of adaptation and standardization but without significantly adjusting the descriptions to the specific culture, the culture of individual countries is significantly present in the descriptions on Volkswagen profile. This can be also the reason why Volkswagen proved to be the most efficient among the other automotive companies.

\section{Land Rover UK}

The British, primary profile of Land Rover uses mainly videos to present the skills and the technology of Land Rover cars set in nature. Many posts mention and show the photos of people, mostly sportsmen, supported by Land Rover. We are not talking only about adults, but also kids practicing extreme sports. profile also publishes posts showing famous people testing Land Rover cars. Even on this Facebook profile, we can observe the cultural specifics of the UK that we have already mentioned. Based on the historical experience, there is prevailing individualism and masculinity presented through people and famous figures in the posts.

\section{Land Rover France}

It is typical for the French Facebook profile to display success and victory in their own posts covering $29.92 \%$ of all posts. The profile uses the expressions such as "the best" or "the most universal in the world" in many posts. The posts present the French success through different sportsmen and contestants supported by Land Rover. The substantial difference from the UK Facebook profile can be observed here. Photos and videos are set in the French cities as well as nature and we can also see the French flag. It important for the French to show themselves as the best, which is associated with the famous French history mentioned in the previous interpretations.

\section{Land Rover Sweden}

The Swedish profile focuses on difficult conditions that can be easily overcome by Land Rover cars. However, most of the posts are adopted from other Facebook profiles. Posts are not set in the Swedish environment, but for example in a dessert 
proving that Land Rover cars can handle such conditions as well. This idea is also conveyed in one of the statuses, which says that Land Rover is a car for all seasons. On one hand, there is a topic of overcoming difficult conditions, typical for the Swedish culture. On the other hand, only few own posts (13.85\%) are set in the Swedish hostile environment.

\section{Land Rover Germany}

Analysis of German Facebook profile brings interesting findings. Mainly in the case of Volkswagen and Volvo, not so significantly in the case of Peugeot, the own posts were focused on the improvement of productivity and efficiency through the cars of individual brands. In the case of Land Rover we can see the lower percentage of own posts (only $21.58 \%$ ), and even those are not very specific and are not carrying the cultural imprint of this country. The profile posts news about the meeting of veteran cars, a few photographs from fans and also selling offers for the German market.

\section{Land Rover Slovakia}

When compared to other automotive companies, the Slovak Facebook profile uses the strategy of adaptation in the lowest extent with only $7.89 \%$ of own posts.

\section{Summary of Land Rover}

Even with this last analysed automotive company we observe the elements of adaptation and standardization with largely reflected cultural influence of individual states. Interesting fact is that this automotive company is the least active one (published the lowest amount of posts) in comparison to others. From the point of view of efficiency, it comes second after Volkswagen. This can be explained by pragmatism, typical British feature, which may be reflected in this case.

Based on the analysis and interpretation of cultural forms we can create the overview of all countries and their culture. (Table 3)

Table 3. Percentage of own posts of automotive companies

\begin{tabular}{|c|c|c|c|c|}
\hline & Sweden & Germany & France & Great Britain \\
\hline $\begin{array}{l}\text { Cultural } \\
\text { forms }\end{array}$ & $\begin{array}{l}\text { harsh Nordic } \\
\text { environment }\end{array}$ & $\begin{array}{c}\text { conveniences and } \\
\text { accessories of cars } \\
\text { which improve the } \\
\text { efficiency } \\
\text { cars and people and } \\
\text { how they are used } \\
\text { car as a helper in } \\
\text { usual activities } \\
\text { the evolution of } \\
\text { model Golf } \\
\text { animals and nature }\end{array}$ & $\begin{array}{l}\text { photographs in the } \\
\text { French cities, } \\
\text { historical sites and } \\
\text { countryside } \\
\text { French } \\
\text { accomplishments } \\
\text { famous French } \\
\text { history } \\
\text { French "imprint" }\end{array}$ & $\begin{array}{l}\text { ordinary people and } \\
\text { their stories } \\
\text { sportsmen, famous } \\
\text { figures and their } \\
\text { achievements }\end{array}$ \\
\hline
\end{tabular}

Source: Authors' own research. 


\section{Conclusions}

The concept of intercultural marketing in a current boom of social media that participate on creation of the global market is becoming the basis for marketing communication of international companies. This trend can be observed also in automotive companies. Based on our study we can state that automotive companies use the combination of standardisation and adaptation. Their marketing communication is based on the common strategy including also standardised marketing materials, but majority of company Facebook profiles produce their own content and adapt it in a certain level for local conditions. Facebook profile administrators also confirm this practice.

Our results prove that the use of standardisation and adaptation is not related to efficiency of marketing communication of individual Facebook profiles and automotive companies. One of the factors that determine the efficiency is cultural specifics. Even though the automotive company Peugeot is combining the elements of standardisation and adaptation in the researched countries, the posts produced by individual Facebook profiles are strongly influenced by the French culture and the local culture (e.g. in Sweden) is in the background. From the point of view of efficiency of marketing communication, Peugeot turned out to be the least efficient. On the other hand, the Volkswagen automotive company has the most efficient marketing communication. It also combines standardisation and adaptation, but the original posts produced by individual Facebook profiles were strongly influenced by the local culture of countries which we followed on their Facebook profiles. We can see that adaptation was focused directly on the cultures, which was not significantly noticeable with Peugeot. Mentioned cultural differences were analysed through cultural forms. While making interpretations through cultural forms, we could identify what is generally typical for individual Facebook profiles from the cultural point of view. It was interesting to find out that also on Facebook as a social media platform, the cultural specifics of individual countries based on their historical experience are manifested. Harsh Nordic environment in Sweden, fame and accomplishments in France, importance of efficiency in Germany, or focus on the famous figures and individuals in Great Britain can serve as illustrative examples. Regarding cultural forms, Slovak Facebook profiles were specific. Due to the continuous and quick evolution of the culture caused by several political changes in Slovakia in recent century, it was very difficult to generalise cultural forms and interpret them.

Based on our results we can conclude that reasonable adaptation to the local culture is the key to the success and mainly to the efficiency, but we are also aware that efficiency is influenced by several factors, which should be the subject of research in the future. We mean the impact of the subjective opinions and attitudes of Facebook profiles administrators, but also subjective attitude of authors of this research, which could have been reflected in the analysis and evaluation of the posts. In future, it would be appropriate to include more experts in the research to ensure the objectivity of the qualitative analysis. In order to guarantee better possibility of generalising the results, it would be also useful to analyse and examine other automotive companies in a global scale. Intercultural marketing and 
marketing communication include also other elements we can focus on in future. To be more specific, we mean the selling of the cars, analysis of specific activities on social media through exact statistical data, but also the composition of the fan base.

\section{References}

Bajzíková, L., Šajgalíková, H., Wojčák, E. and Poláková, M. (2014), “Dynamics of changes toward knowledge-based economy in Slovak SMEs", Procedia Social and Behavioral Sciences, Vol. 150, pp. 637-647.

Azar, S., Machado, J., Vacas-De-Carvalho and L., M. A. (2016), "Motivations to interact with brands on Facebook - Towards a typology of consumer-brand interactions", Journal of Brand Management, Vol. 2, No. 23, pp. 153-178.

Dessart, L., Veloutsou, C. and Morgan-Thomas, A. (2015), "Consumer engagement in online brand communities: A social media perspective", Journal of Product and Brand Management, Vol. 1, No. 24, pp. 28-42.

Direction, S. (2016), "Social media as the path to a marketing strategy: Companies must become "curators" to meet the challenge", Strategic Direction, Vol 2 No. 32, pp. 20-22.

Droppa, M., Budaj, P. and Mikuš, P. (2013). "An organisational culture and the process performance of the organisation." in: An organisational culture and the process performance of the organisation, Association internationale SÉCT: Fribourg, p. 27.

Gong, W., Stump, R. L., and Li, Z. G. (2014), LGlobal use and access of social networking web sites: A national culture perspective”, Journal of Research in Interactive Marketing, Vol. 1, No. 8, pp. 37-55.

Gonzalez-Lafaysse, L. and Lapassouse-Madrid, C. (2016), "Facebook and sustainable development: A case study of a French supermarket chain", International Journal of Retail and Distribution Management, Vol. 5, No. 44, pp. 560-582.

Guo, L. et al. (2015), "Documenting business-to-consumer (B2C) communications on facebook: What have changed among restaurantsand consumers?", Worldwide Hospitality and Tourism Themes, Vol. 3, No. 7, pp. 283-294.

Hamilton, M., Kaltcheva, V. and Rohm, A. (2016), "Social Media and Value Creation: The Role of Interaction Satisfaction and Interaction Immersion", Journal of Interactive Marketing, Vol. 36, pp. 121-133.

He, W. et al. (2015), "A novel social media competitive analytics framework with sentiment benchmark", Information and Management, Vol. 7, No. 52, pp. 801812.

Hofstede, G. (1980), Culture's consequences: International differences in work-related values, Sage Publications: Beverly Hills.

Hrnčiar, M. and Madzík, P. (2016), "A change in the conception of the factors which form customer expectations", Johannes Kepler Universitat Linz: Podebrady, pp. 145-152.

Hudson, S., Huang, L., Roth, M. and Madden T. (2016), "The influence of social media interactions on consumer-brand relationships: A three-country study of brand perceptions and marketing behaviors", International Journal of Research in Marketing, Vol. 1, No. 33, pp. 27-41. 
Icha, O. and Edwin, A. (2016), "Effectiveness of social media networks as a strategic tool for organizational marketing management", Journal of Internet Banking and Commerce, Vol. 21, pp. 20.

Järvinen, J. and Taiminen, H. (2016), "Harnessing marketing automation for B2B content marketing", Industrial Marketing Management, Vol. 54, pp. 164-175.

Karjaluoto, H., Mustonen, N. and Ulkuniemi, P. (2015), "The role of digital channels in industrial marketing communications", Journal of Business and Industrial Marketing, Vol. 6, No. 30, pp. 703-710.

Khan, I., Han. DP. and Wahab, A. (2016), "Does culture matter in effectiveness of social media marketing strategy? An investigation of brand fan pages", Aslib Journal of Information Management, Vol. 68, No. 6, pp. 694-715.

Kilgour, M., Sasser, S. and Larke, R. (2014), "The social media transformation process: Curating content into strategy", Corporate Communications, Vol. 3, No. 20, pp. 326-343.

Kotler, P. and Keller, K. L. (2007), Marketing management, Grada Publishing: Praha.

Kwok, L. and Yu, B. (2013), "Spreading social media messages on facebook: an analysis of restaurant business-to-consumer communications", Cornell Hospitality Quarterly, Vol. 1, No. 54, pp. 84-94.

Naylor, R., Lamberton, C. and West, P. (2012), "Beyond the "like" button: The impact of mere virtual presence on brand evaluations and purchase intentions in social media settings", Journal of Marketing, Vol. 6, No. 76, pp. 105-120.

Niedermeier, K., Wang, E. and Zhang, X. (2016), "The use of social media among business-to-business sales professionals in China: How social media helps create and solidify guanxi relationships between sales professionals and customers". Journal of Research in Interactive Marketing, Vol. 1, No. 10, pp. 33-49.

Šajgalíková, H. and Bajzíková, L. (2013), Organizácia a kultúra, Ofprint: Bratislava.

Šajgalíkova, H. and Copuš, L. (2016), "Vzt’ah národnej kultúry a vybraných funkcií manažmentu”, VERBUM: Ružomberok, pp. 360-369.

Schultz, D. and Peltier, J. (2013). "Social media's slippery slope: challenges, opportunities and future research directions", Journal of Research in Interactive Marketing, Vol. 2, No. 7, pp. 233-237.

Sharma, S., Joshi, A. and Sharma, H. (2016), "A multi-analytical approach to predict the Facebook usage in higher education", Computers in Human Behavior, Vol. 55, pp. 340-353.

Telang, A. and Deshpande, A. (2016), "Keep calm and carry on: A crisis communication study of Cadbury and McDonalds", Management and Marketing. Challenges for the Knowledge Society, Vol. 11, No. 1, pp. 371-379.

Trice, H. M. and Beyer, J. M. (1993), The cultures of work organizations, Englewood Cliffs: Prentice Hall.

Valos, M. et al. (2016), "Exploring the integration of social media within integrated marketing communication frameworks: Perspectives of services marketers", Marketing Intelligence and Planning, Vol. 1, No. 34, pp. 19-40. 